\title{
Assessment of the physical flood susceptibility of buildings on a large scale - conceptual and methodological frameworks
}

\author{
A. Blanco-Vogt ${ }^{1}$ and J. Schanze ${ }^{1,2}$ \\ ${ }^{1}$ Chair of Environmental Development and Risk Management, Faculty of Environmental Sciences, Technische Universität \\ Dresden, Dresden, Germany \\ ${ }^{2}$ Leibniz Institute of Ecological Urban and Regional Development (IOER), Dresden, Germany
}

Correspondence to: A. Blanco-Vogt (angela.blanco@mailbox.tu-dresden.de)

Received: 20 August 2013 - Published in Nat. Hazards Earth Syst. Sci. Discuss.: 17 October 2013

Revised: 11 March 2014 - Accepted: 17 March 2014 - Published: 19 August 2014

\begin{abstract}
There are various approaches available for assessing the flood vulnerability and damage to buildings and critical infrastructure. They cover pre- and post-event methods for different scales. However, there can hardly be found any method that allows for a large-scale pre-event assessment of the built structures with a high resolution. To make advancements in this respect, the paper presents, first, a conceptual framework for understanding the physical flood susceptibility of buildings and, second, a methodological framework for its assessment. The latter ranges from semi-automatic extraction of buildings, mainly from remote sensing with a subsequent classification and systematic characterisation, to the assessment of the physical flood susceptibility on the basis of depth-impact functions. The work shows results of the methodology's implementation and testing in a settlement of the city of Magangué, along the Magdalena River in Colombia.
\end{abstract}

\section{Introduction}

Analyses of the flood susceptibility of buildings are scarce, which may negatively infer the proper and efficient allocation of risk reduction measures (e.g. UNISDR, 2004). There are various approaches available for assessing the flood damage to buildings and critical infrastructure based on field data collected after an event, such as FLEMO (Flood Loss Estimation MOdel; Kreibich et al., 2010), as well as synthetic approaches for assessing the damage prior to a future event, as e.g. HAZUS (HAZards United States; Scawthorn et al., 2006) and HOWAD (Flood Damage Simulation Model; Neu- bert et al., 2014). The differences between the assessment models for flood vulnerability and flood damage of buildings in terms of scale, input data, damage calculation and outputs with their uncertainties are shown by Merz et al. (2004) and Jongman et al. (2012). However, up to now, these methods cannot be easily transferred to a large-scale and highresolution assessment along large rivers because of insufficiently detailed scales of land-use maps, non-existence, outdated state or restricted accessibility of cadastral and other data, lacking classification and characterisation approaches for the built structures and extensive time and resource consumption of required field work for damage analyses.

Most frequently, institutions use questionnaires or forms for the assessment of damages after flood events, but the results of these surveys do not always cover a spatial reference, or they are not interrelated, or the forms are filled by experts who have different levels of knowledge about the damage assessment. This makes the systematic analysis of vulnerability and exposure a challenge. Moreover, the validity of findings is difficult to judge due to the huge variety of methods, models and tools applied.

Against this background, a novel approach is proposed that particularly enables the classification and characterisation of buildings on a large scale as well as a systematic physical flood susceptibility assessment. High-resolution images and digital surface models are used as a data source for the building analysis because they are supposed to capture huge multidimensional information on settlement features in an instant of time and allow for a high efficiency through principal global availability and relatively low costs compared to the 


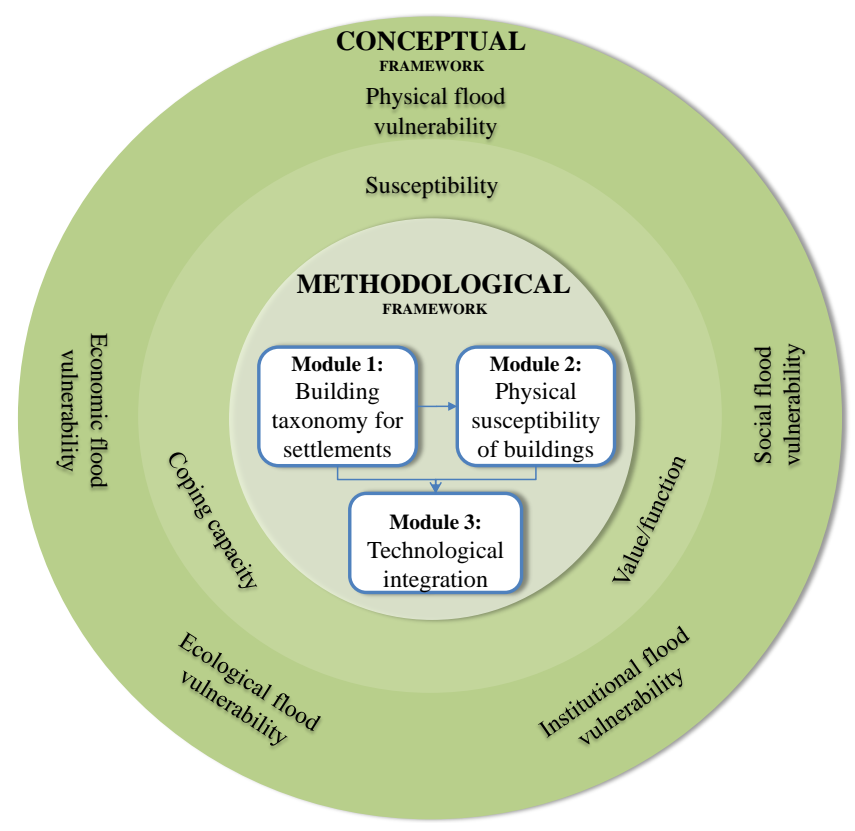

Figure 1. Frameworks of the methodology with dimensions of sustainability (outer circle), components of vulnerability (middle circle) and the modules (inner circle).

surveying of the parameters on the ground (Navulur, 2006; $\mathrm{Vu}$ and Ban, 2010).

Here, the conceptual and methodological frameworks and results of the implementation and testing of a methodology are presented. The conceptual framework supports an indepth understanding of the physical aspects of vulnerability and its influence on social and economic vulnerabilities. Furthermore, it describes key features that shape the physical flood susceptibility of buildings.

The methodological framework comprises three modules: (i) methods for setting up a building taxonomy for settlements, (ii) methods for assessing the physical susceptibility of buildings and (iii) methods for a technological integration of the two modules using computer-based tools. The testing of the methodology was carried out in a study site of a developing country selected according to the availability of data.

\section{Conceptual framework}

With physical flood susceptibility, the paper addresses one key aspect of vulnerability. The concept of vulnerability has evolved from specific fields related to various hazards. For instance, Thywissen (2006) presents 35 definitions of vulnerability. Detailed concepts of vulnerability have been provided by numerous authors, such as Blaikie et al. (1994), Birkmann (2006) and Messner et al. (2007). The latter even summarise some indicators and criteria for determining vulnerability. According to UNISDR (2004), vulnerability gen- erally is "the characteristic of a system that describes its potential to be harmed."

Schanze (2006) proposes to understand vulnerability as a "mathematical" function of susceptibility, value or function and coping capacity of a system considering the physical, ecological, economic, social and institutional dimensions (see Fig. 1). For buildings, the physical dimensions of susceptibility, function and coping capacity can be conceived as follows.

Susceptibility is understood, in the case of buildings, as their propensity to experience harm (Samuels et al., 2009) and determined by their structural design, intrinsic properties and the material used (Naumann et al., 2010). The susceptibility is related to fragility, weakness, sensibility or instability, here applied to a building which can suffer a physical impact, degradation, failure, loss of structural integrity or deformation of its materials and its components, causing incapacity of the building's functionalities.

The function of buildings may be seen as the purpose for which they are designed or exist. Basic building functions are to support dead loads, live loads and environmental loads (Ochshorn, 2009), such as the protection of their inhabitants from rainwater, rough weather, to safeguard them against invaders and enemies, to provide a static structure for their activities or demonstrate a social status or lifestyle through the inventory, furniture or design.

Coping capacity in terms of buildings can be understood as their resilience (Brauch and Oswald Spring, 2011), which may be considered as the ability to quickly and efficiently regain the initial state after an impact (cf. Naumann et al., 2010). Evans et al. (2006) define the physical resilience of buildings as protective elements that allow the constructions to recover quickly and easily.

Physical flood vulnerability is strongly linked to the social and economic vulnerability as the disturbance of the physical elements immediately interrupts or disjoins social and economic activities. For instance, the WHO (2009) finds sufficient evidence to link health problems to building moisture and biological agents, caused for example by sanitary sewer lines to back up into buildings through drain pipes or contaminated water from fuel tanks. Allergies or respiratory diseases may potentially be triggered by the presence of mould, muck, insects or toxic sludge in the building's materials after a flood. It could be inferred that people living in houses with moisture are susceptible to particular diseases, infections or allergic reactions.

Moreover, structural impacts on buildings might be one reason why people migrate or temporally or permanently move to other neighbourhoods. Therefore, in the social dimension, the estimation of potential negative consequences caused by a flood could be supported by an assessment of flood impacts on buildings.

The estimation of an economic flood vulnerability might be assessed according to the impacts on buildings in combination with economic data. For instance, the assessment of 
the physical vulnerability may provide the basis for the calculation of reconstruction costs, economic losses in stocks and depth-damage functions. This information might likewise support the analysis of a potential compensation for losses depending on the quality of the socio-economic information. Hence, potential consequences are categorised through a diverse typology, i.e. direct and indirect impacts or damages, which can be tangible or intangible. Tangible damages can be specified in monetary terms; intangible damage is usually recorded by non-monetary measures (Messner et al., 2007).

Therefore, physical flood vulnerability is not only understood as a mere component of risk and risk management, but it can also be seen as a basic element for determining with better precision the interaction of people with the safety of their environment (UNEP, 2002). Reciprocally, the economic coping capacity regarding buildings requires the analysis of the economic resources for recovery or reconstruction activities. Hereby, the physical flood susceptibility is always a component of the physical flood vulnerability with both belonging to a flood risk system (cf. Schanze, 2006).

Merz et al. (2004) identify the need for refinement and standardisation of data collection for flood damage estimation, and state that current depth-damage functions may contain a large uncertainty. Additionally, these functions present relevant differences for damage assessment in terms of "damage categories, degree of detail, scale of analysis, the application of basic evaluation principles (e.g. replacement costs, depreciated costs), and the application or non-application of results in benefit-cost and risk analyses" (Meyer and Messner, 2005).

To make a step forward, particularly towards a systematic, transferable and standardised process, a reliable building typology approach for supporting a pre-event assessment of the physical flood susceptibility at a large scale is required. Beyond, there is a need for methods that assist in standardised data collection on the building susceptibility on an overview level. Not least, detailed damage analyses should be advanced to improve the validity of local in-depth investigations and hence enable simulations of future vulnerabilities and risks. The proposed methodological framework focuses on the building typology approach and the standardised susceptibility assessment on a large scale.

\section{Methodological framework}

The operationalisation of the conceptual framework focuses on the physical dimension of sustainability on the one hand and on susceptibility as one of the components of vulnerability on the other hand. It makes use of three modules which refer to all relevant aspects influencing the physical flood susceptibility of buildings (Fig. 1). The modules set the frame for methodological requirements and can deal with alterna- tive methods. The assessment is supposed to follow the numerical order of the modules.

The first module, building taxonomy for settlementsis dedicated to set-up of a building typology in the way of a building taxonomy. This is based on the extraction of parameters from remote sensing data and GIS analysis. The building taxonomy allows to reduce the analysis of the building susceptibility to representatives of each buidling type, why surveys need not to be done one by one, which would be very expensive. Instead, information can be transferred to other buildings with similar characteristics. The identification of representative buildings is based on statistical analyses and membership functions.

The second module, physical susceptibility of buildings, refers to the assessment of representative buildings from each building type with the aim of deriving principal depthphysical impact functions. It relates the relevant building components including their heights, their dimensions and their materials to the susceptible volume of the building materials at different water levels. The material's susceptibility is estimated on the basis of literature research and/or expert judgments. Depth-physical impact functions are derived from interrelations between the water level and the susceptible volume.

The third module, technological integration, provides the computer and mobile tools for the operationalisation and automation of major methods. Thus, tools for the integration of the building taxonomy and the depth-physical impact functions of representative buildings are developed to support the automatic processing. This module is supposed to be potentially integrated into a spatial decision support tool (SDSS) as proposed by McGahey et al. (2009).

\subsection{Module 1: building taxonomy for settlements}

A building taxonomy can serve as a means of structuring settlements for a more detailed analysis in large river floodplains. Based on findings from earthquake engineering research (Brzev et al., 2011), which is creating an initial (beta) version of a building taxonomy for the World Housing Encyclopedia (WHE), a building taxonomy is developed in order to cluster similar buildings in a group for reducing the effort to investigate the buildings. The presented approach modifies the proposal from Brzev et al. (2011), which only involves parameters describing the contextual information, geometric and roof surface characteristics.

The building taxonomy approach at first requires identification of the individual buildings. This can be done through a predominantly semi-automatic extraction from remote sensing data, depending on "the resolution of data, especially of the high data, on the selected method, on the scene complexity and incomplete cue extraction" (Sohn and Dowman, 2007). Once the buildings are identified, parameters or attributes may be discretised into classes called categories. A compendium of all categories can then be arranged in 
Table 1. Range of categories for the seven parameters of the building taxonomy.

\begin{tabular}{|lll|}
\hline \multicolumn{1}{|c|}{ Parameter } & Code & Description \\
\hline \multirow{2}{*}{ Height } & 1 & $<=7.5 \mathrm{~m}$ \\
& 2 & $>7.5-13 \mathrm{~m}$ \\
& 3 & $>13-30 \mathrm{~m}$ \\
\hline \multirow{3}{*}{ Size } & 1 & $0-50 \mathrm{~m}^{2}$ \\
& 2 & $>150-500 \mathrm{~m}^{2}$ \\
& 3 & $>500-800 \mathrm{~m}^{2}$ \\
Elongatedness & 4 & $>800-1000 \mathrm{~m}^{2}$ \\
(length/width ratio) & 1 & Square: $0.8-1.2$ \\
Roof form & 2 & Elongated rectangle: $>0.8$ and $<1.2$ \\
\hline \multirow{2}{*}{ Roof slope (Roof pitch) } & 1 & $<=12$ vertices \\
& 2 & $>12$ vertices \\
\hline \multirow{2}{*}{ Index inversely compactness } & 1 & $<=10$ degrees \\
& 2 & $>10$ degrees \\
\hline \multirow{3}{*}{ Adjacency } & 1 & $>66 \%$ \\
& 2 & $>33 \%$ - $66 \%$ \\
& 3 & $<=33 \%$ \\
\hline & 1 & All sides exposed to open space \\
& 2 & At least three sides exposed to open space \\
& 3 & Two sides exposed to open space \\
& 4 & One side exposed to open space \\
\hline
\end{tabular}

codes and leads to the building taxonomy. Finally, some representative buildings of each building type are selected for a posterior assessment.

\subsubsection{Extraction of buildings from VHR data}

Very high resolution (VHR) images from satellite sensors and aerial photos directly provide a lot of different levels of information on many phenomena, allow for a differentiation of elements on the urban fabric such as building characteristics and even facilitate investigation of the temporal changes in an area (Fugate et al., 2010; Mesev, 2010).

Blanco-Vogt et al. (2013) describe how these parameters play a particular role in setting up building typologies in the context of flood susceptibility assessment using very-highresolution spectral data together with digital surface models. Sohn and Downan (2007), Rutzinger et al. (2009) and Brenner (2010) demonstrate a huge variety of methods and data sources for the extraction of different building features. Hence, the extraction of building features cannot be carried out with just one method or follow a unique algorithm. Instead, its results depend on the data sources, the quality of the data, the methods and the reached accuracy.

The proposed building taxonomy approach bears on veryhigh-resolution spectral and elevation data for gathering building parameters that are essential for the characterisation of the physical construction. The initial parameters are building outline, building height and building roof slope. Once the building outline has been extracted, the parameters size, elongatedness, roof form, adjacency and compactness can be de- rived. Building height and building roof slope depend on the ground samples from digital surface models.

\subsubsection{Derivation of the building taxonomic code}

The parameters mentioned above are determined through continuous values (size, height, elongatedness and roof slope); discrete variables (adjacency and roof form) and interval-scale variables as the values are ranked (compactness). It is important to note that building attributes are not always distributed according to a bell curve and the patterns of parameter values are not predictable.

An approach for finding patterns and classes between the building's characteristics is coding the data (Adriaans and Zantinge, 1996). Coding information allows for a systematic identification of variables which values facilitate their validation. The data codification for each parameter corresponds to a category describing the building's characteristics. The coding is initiated by induction. Each parameter is codified on the basis of the building's initial description; those categories are then improved in function of the emerging theoretical questions and the results from the empirical application.

The borders of the classes are adjusted through (i) statistical analyses (histogram diagram, scatter diagram and the correlation matrix) in order to find trends and relations among the parameters and (ii) advice from experts (e.g. civil engineers, architects) who discuss the relevance of the classes for the subsequent susceptibility assessment. The building taxonomic code associates the quantitative data with the qualitative data of the categorisation. The validation is done by visually comparing the building's characteristics with the codes 


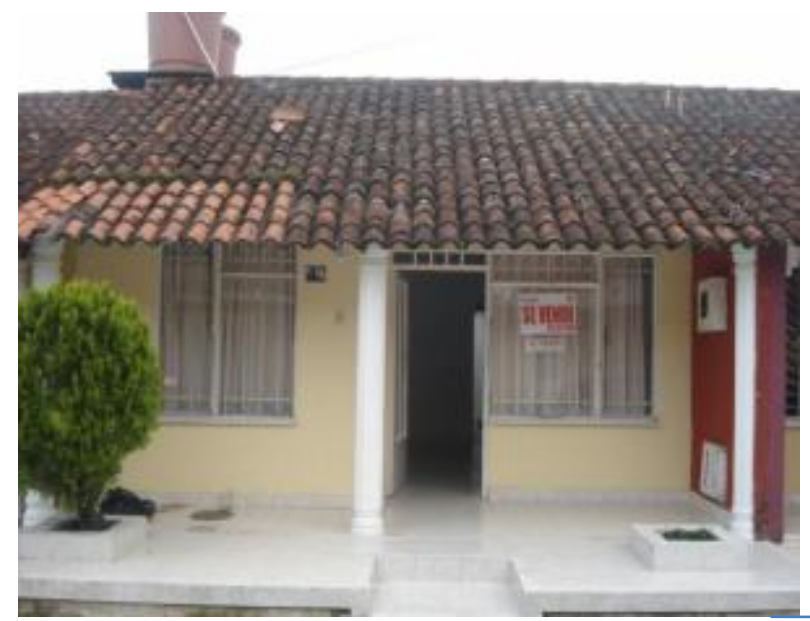

$250 \mathrm{~cm}$ Foundation, floor, facade, electrical and gas installations, doors, furniture, walls, telecommunication lines, water pipes, windows, internal ceiling, roof

$180 \mathrm{~cm}$ Foundation, floor facade, electrical and gas installations, doors, furniture, windows, walls, telecommunication lines, water pipes, internal ceiling

$100 \mathrm{~cm}$ Foundation, floor, facade, electrical and gas instalations, doors, furniture, walls, telecommunication lines, water pipes, windows

$60 \mathrm{~cm}$ Foundation, floor, facade, electrical and gas

installations, doors, walls, telecommunication lines,

water pipes, furniture

$30 \mathrm{~cm}$ Foundation, floor, facade, electrical

and gas installations, doors, walls

$10 \mathrm{~cm}$ from the terrain: Foundation and floors

Figure 2. Relevant components of the building exposed to water depths.

revealing building patterns. As a result of this process, Table 1 discloses the categories and codes for every parameter.

For instance, the code "1111111" describes from left to right: a short building (1st digit: height); size less than $150 \mathrm{~m}^{2}$ (2nd digit: size); with square form in the space ( $3 \mathrm{rd}$ digit: elongatedness); very simple form (4th digit: roofform) and flat roof (5th digit: roof pitch); open space around the building larger than $66 \%$ (6th digit: compactness) and all sides exposed to open space (7th digit: adjacency). Two additional examples of the taxonomic code are displayed in Fig. 3 . The pictures show that the buildings with the code " 1221123 " present similar roof eaves, whereof the buildings with the taxonomic building code " 2121134 " have a balcony and similar roof construction.

\subsubsection{Selection of representative buildings}

Representative buildings have been selected from each building type as samples for the subsequent assessment of potential flood impacts (see Sect. 3.2). The selection of representative buildings of each type allows for the transfer of knowledge from in-depth investigations of individual buildings to other buildings with similar characteristics.

Representative buildings stand for "typical", "prototype", "archetypal" or "common" buildings in a study area. Using histograms, the representativeness of the taxonomic codes with a higher frequency in a particular settlement can be separated. The other buildings with a lower frequency are called non-representative buildings.

An approach for finding similarities between representative buildings and non-representative buildings is grouping the data using cluster analyses (MacQueen, 1967), which allows for the identification of groups of objects with similar patterns but differences from individuals in other groups. The selected representative buildings are the $K$ clusters which contain $p$ quantitative parameters. The similarities between non-representative buildings and representative buildings are compared, taking values between 0 and 1 , the "crisp" values belonging to a membership function. A membership function provides a measure of the degree of similarity of an element to a fuzzy set and helps to identify the borders between the typologies, where they are inherently vague (Coppi et al., 2006).

The sum of the assigned values gives the percentage of matching with a representative building. Then, the nonrepresentatives are grouped to the building type with the largest values of membership depending on the degree of similarity. A threshold of similarity of $80 \%$ was selected for grouping the non-representatives to the representatives. The buildings below this threshold are considered as atypical and hence also selected for the assessment. Inductive reasoning, iterative processes as well as trial and error help to generate the membership functions and the rules for selecting the value of the sum for the matching in order to minimise the entropy for every case study.

\subsection{Module 2: physical susceptibility of buildings}

Once the representative buildings in the study area have been selected, the assessment of their physical flood susceptibility is carried out. For this purpose, the potential flood impacts for representative buildings are analysed according to (i) the identification of building components, (ii) the assessment of the building materials' susceptibility and (iii) the derivation of depth-physical impact functions.

\subsubsection{Identification of building components}

The identification of building components consists of (i) the recognition of relevant building components, (ii) the measurement of their upper and lower height above ground, (iii) the measurement of their relevant dimensions, (iv) the dis- 


\begin{abstract}
'1221123'
One storey, footprint size between $150 \mathrm{~m}^{2}$ and $500 \mathrm{~m}^{2}$, rectangle form in the terrain, roof form with less than 12 vertices, flat roof, open space area between 33 $\%$ and $66 \%$ and two sides exposed to open space.

\section{'2121134'}

Two storeys, footprint size between $150 \mathrm{~m}^{2}$ and $500 \mathrm{~m}^{2}$, rectangle form in the terrain, roof form with less than 12 vertices, flat roof, open space area less than 33 $\%$ and one side exposed to open space.
\end{abstract}
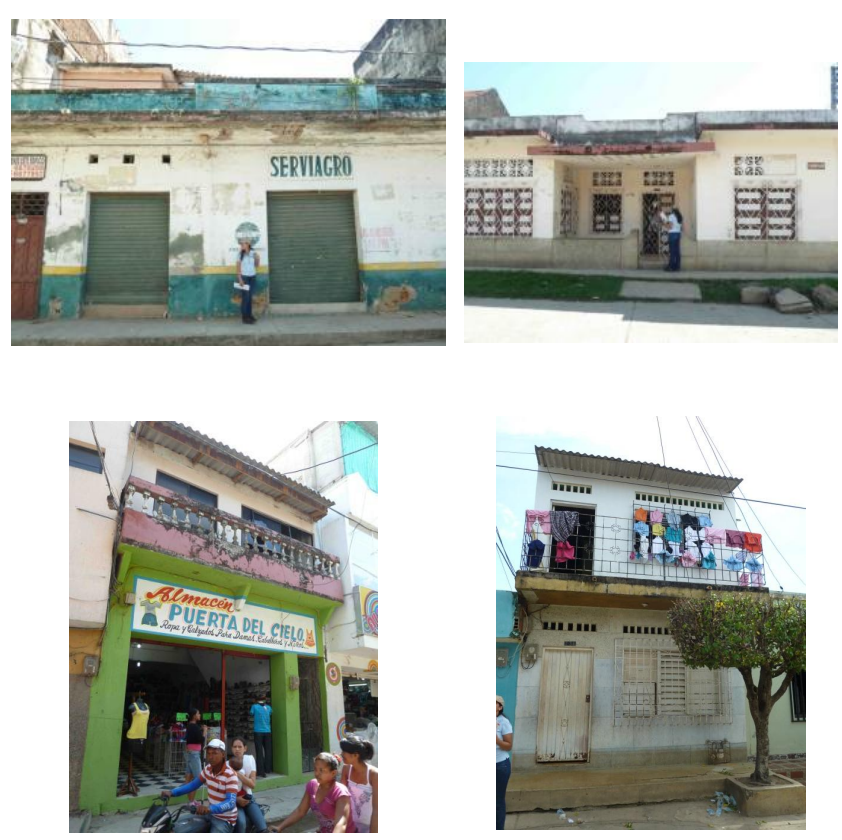

Figure 3. Examples of building constructions with the taxonomic code according to Table 1.

tinction of the relevant materials and (v) the calculation of the material volume.

Building components can be categorised into structural components, shell components, non-structural components, connectors, inventory and finish components. An example of the list of shell, structured, non-structured and inventory components that can be exposed to different water depths is depicted in Fig. 2.

Non-invasive methods can be carried out for analysing the structure and shell components of buildings, such as the presence of basements, external windows, external doors, façades, external walls, some roof characteristics, balconies, columns, beams and slabs. These components must at least be distinguished and inventoried for a building susceptibility assessment. The components can be specified according to their position above the ground and related to water depths that could cover them.

The building size, perimeter, height, roof slope, width and length are calculated from the features extracted using the very-high-resolution data. The additionally required dimensions can be measured by mobile mapping, multidirectional imaging, terrestrial photogrammetry, laser instruments, apps, metre sticks, information provided by the manufacturer or known standard dimensions for the calculation of the components' volume.

The survey allow the experts to identify construction processes and material used for the representative buildings as well as the name of the materials for the region, as a material's name can vary depending on the area. Finish materials may not be taken into account because of their diversity and complexity for differentiating them.

\subsubsection{Assessment of the building material's susceptibility}

Susceptibility means that the material will be harmed, worn or degraded due to the flood. Contrary to susceptibility, resistance and resilience are often viewed as a positive property, meaning a receptor's ability to withstand an impact without significant alteration (resistance) or to be easily reconstructed (resilience; e.g. Naumann et al., 2010).

As a first step, the building material's resistance can be analysed according to international studies, such as BMVBS (2006), Committee and Resources (2006), Escarameia et al. (2006) and FEMA (2008), which qualify the material's resistance with linguistic terms. For this investigation, the lists of materials from the four institutions were compared and some similarities in the qualification were found, such as the qualification of resistance in brick face, common brick and standard plywood. There are also some differences in the quality of the material's resistance, depending on where the material is used within a component. Here, it is assumed that susceptibility is the opposite of resistance.

As a second step, expert knowledge may assist the qualification of susceptibility depending on the use of materials and on detailed information about the material's properties. Aglan et al. (2004) describe some material's properties which can be observed, inspected and monitored using the human senses. 
The material's properties selected for the qualification are resistant characteristics after flooding (shearing, flaking/scaling, bending, cracks, buckling, swollen, none); general appearance (discoloured surfaces, efflorescence due to crystalline deposits of alkaline salts, none); biological and chemical reaction characteristics (mould growth, spreading odours, contamination due to intern components, oxidation, none) and natural drying speed in number of days and, if available, technical standards and construction specifications based on ISO standards or codes produced by manufacturer associations. Those properties should be documented, assessed and recorded photographically. The highest assessed value reflects that the material can generate the collapse of the component. The monitoring of the buildings' properties can support susceptibility assessments in other areas. The formulas proposed by Hong and Lee (1996) are considered for determining the fuzzy sets with their crisp values of the material's susceptibility.

\subsubsection{Derivation of depth-physical impact functions}

These functions are developed in order to support damage assessment overcoming the lack of monetary values or refurbishment cost data. Similar to depth-damage functions, depth-physical impact functions are derived as a relationship between the depth of a flood and the susceptibility of the impacted material volume. Physical impacts on buildings are estimated on the basis of the potential susceptible materials' volume for components calculated in square metres, i.e. degraded material in relation to a maximum susceptibility of 1 . The materials of the components are continuously impacted when the water level rises.

\subsection{Module 3: technological integration}

The two previous modules are integrated using computerbased tools. The system architecture is developed for managing the collected information on the physical flood susceptibility assessment for representative buildings. The users can collect data using smart phones process, transfer and share the information. Various tasks can be carried out automatically, such as the calculation of the parameters, the creation or editing of the taxonomic code and the clustering of building types, the selection of representative buildings and the integration of information in depth-physical impact functions. A database in PostgreSQL can be designed for storing the data and integrating the building taxonomy and depth-physical impact functions using Python scripts of the $\operatorname{ArcGIS}^{\mathrm{TM}} 10$ environment.

\section{Implementing and testing the methodology in a study case}

The following section describes the implementation and testing of the methodology in the settlement Barrio Sur in the city of Magangué, Colombia, located in the floodplain of the Magdalena River.

\subsection{Setting up the building taxonomy}

\subsubsection{Processing a semi-automatic extraction of buildings from remote sensing data}

Planimetric and elevation information are required for the extraction of building features for the derivation of the building taxonomy. Building size, elongatedness, roof form, adjacency and compactness are derived from the planimetric information provided by stereo images of the UltaCAM sensor with a ground sample distance of $0.15 \mathrm{~m}$ and three bands accessible for this study area. Elevation information from precise sources, such as lidar, was not available for this area. Therefore, a DSM (digital surface model) was photogrammetrically generated from the stereo photos for the extraction of the building height and building roof slope. However, the resolution in altitude of this DSM did not exceed $2 \mathrm{~m}$.

The semi-automatic building extraction process consisted in combining masks methods (Awrangjeb et al., 2010) and segmentation processes (Schöpfer et al., 2010). The segmentation was used for dividing the image into regions that are supposed to be the building roofs with similar spectral and topological characteristics. With the help of reference polygons of the building outline, the accuracy of the building extraction is calculated by using the indexes proposed by Song and Haithcoat (2005) and Aguilar and Mills (2008); for a more general discussion of the factors influencing the accuracy, see Sohn and Dowman (2007).

As a result, the building extraction process yielded the detection of only $44 \%$ of the buildings. The inconsistencies for the buildings' extraction in this selected area is due to the presence of corrosion in the roof's materials, the occlusion of the buildings by trees and shadows and the low resolution of the DSM in combination with numerous small buildings. The issue of the DSM's resolution for this area was compensated through validation in the field work. The testing of the methodology in other cases has proved that the proposed resolution of the DSM with $>1 \mathrm{~m}$ significantly improves the accuracy. The buildings that did not fit the criteria of accuracy were manually edited.

\subsubsection{Deriving the building taxonomic code}

Once the building outline was delineated from the orthophotos and the resolution of the DSM was accepted as a preliminary source for the height extraction, the seven parameters were calculated according to Table 1 using the tool for the derivation of the building's taxonomic code for every building. A visual verification of the buildings belonging to the taxonomic code was conducted using pictures of the buildings taken in situ in Colombia and by Google Street View. As a result, 290 buildings in 77 taxonomic building codes 

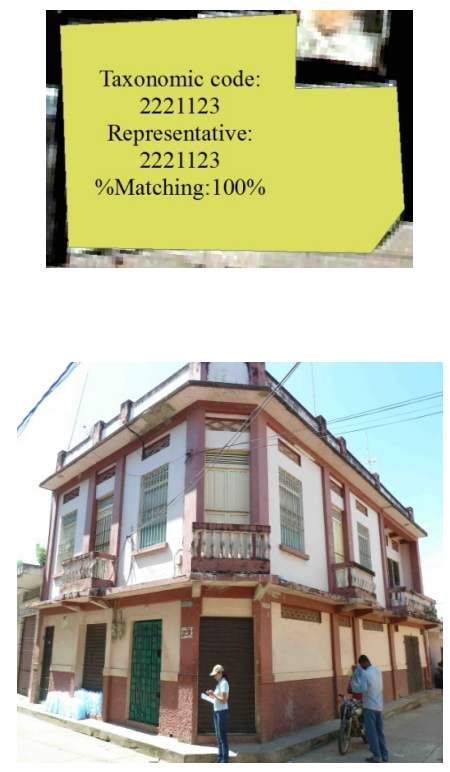
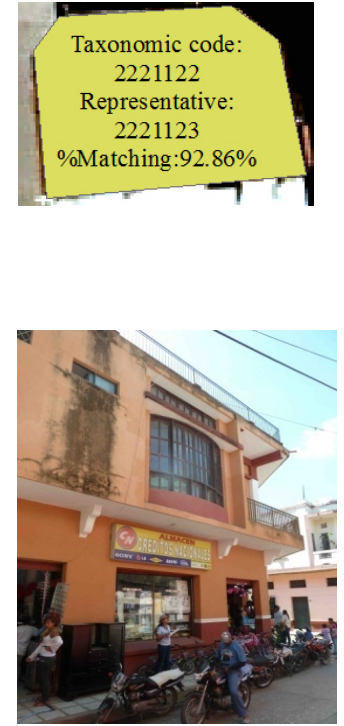
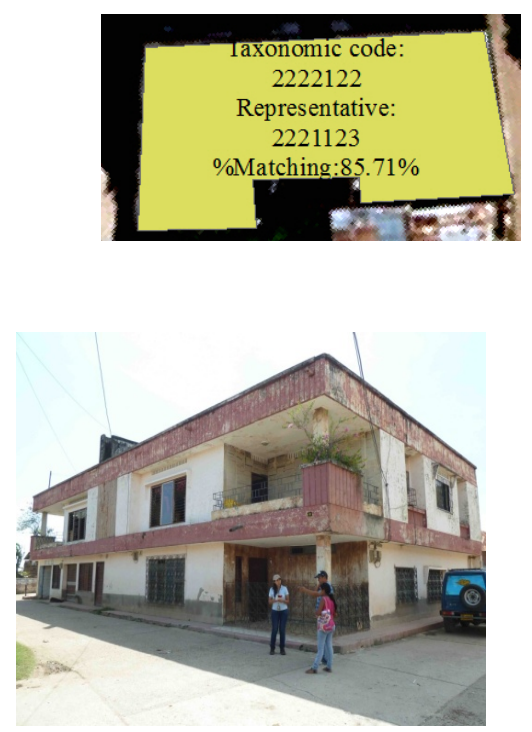

A

B

C

Figure 4. Representative buildings of the taxonomic code "2221123” in Magangué.

were classified in this district. Many building classes can indicate the heterogeneity of the building characteristics in the settlement.

\subsubsection{Selecting the representative buildings}

Based on the histogram, it was decided that nine buildings shall be the threshold for considering the representative buildings, which results in seven groups of representative buildings. Other buildings are non-representative buildings, which were clustered to the representatives using the membership function (Eq. 1). The following function presents the crisp values for a membership function for the seven parameters:

$U_{\mathrm{R}-\text { nonR }}=\left[\begin{array}{lllllll}1 & 1 & 1 & 1 & 1 & 1 & 1 \\ 0.5 & 0.5 & 0.5 & 0.5 & 0.5 & 0.5 & 0.5 \\ 0.3 & 0.3 & 0.3 & 0.3 & 0.3 & 0.3 & 0.3 \\ 0 & 0 & 0 & 0 & 0 & 0 & 0\end{array}\right]$

Figure 4 shows three buildings that were randomly chosen by using the stratified selection of samples, which are clustered to the representative buildings with the taxonomic code "2221123". This taxonomic code represents buildings with two storeys, a size between 150 and $500 \mathrm{~m}^{2}$, a rectangle form in the terrain, a roof form with less than eight vertices, a flat roof, an open space area between 33 and $66 \%$ and two sides exposed to open space. The non-representative building "2222122" (the underlined numbers represent the codes which are different than the codes of the representative build- ings) is clustered to this representative with a percentage of matching of $85.7 \%$ and the non-representative building " 2222123 " is clustered to this representative with a similarity match of $92.86 \%$.

\subsection{Assessment of the buildings' susceptibility}

A published documentation of the resistance of building materials, as reference for the susceptibility qualification, does not exist in Colombia. Four experts were asked to assign the values for the five susceptibility properties described in Sect. 3.2.3. The knowledge of experts allows for a qualification about the resistant characteristics after flooding, general appearance, biological and chemical reaction characteristics, and natural drying speed of shell and structure components.

A first discussion about the susceptibility properties revealed different descriptions of the material's properties after the flood. Therefore, a consensus among the experts was reached based on a simplified Delphi approach. The qualification of the materials has then been computed for obtaining the fuzzy sets of susceptibility (see Table 2).

Building components and building materials were identified and their position above the ground as well as their dimensions were collected in situ using a smartphone app. The susceptible volumes were calculated for these representative buildings as shown in Table 3 for the building " 2221123 ". 
Table 2. Qualification of attributes of susceptibility.

\begin{tabular}{|c|c|c|c|c|c|c|}
\hline Component & Material & $\begin{array}{l}\text { Resistant } \\
\text { characteristics } \\
\text { after flooding }\end{array}$ & $\begin{array}{l}\text { General } \\
\text { appearance }\end{array}$ & $\begin{array}{l}\text { Biological and } \\
\text { chemical } \\
\text { reaction } \\
\text { characteristics }\end{array}$ & $\begin{array}{l}\text { Natural } \\
\text { drying } \\
\text { speed }\end{array}$ & $\begin{array}{l}\text { Fuzzy sets } \\
\text { min.-med.- } \\
\text { max. }\end{array}$ \\
\hline Roof & $\begin{array}{l}\text { Concrete, steel } \\
\text { plate and water- } \\
\text { proofing }\end{array}$ & Peeling & Efflorescence & $\begin{array}{l}\text { Mould growth } \\
\text { and corrosion }\end{array}$ & 2 & $0.30-0.31-0.42$ \\
\hline Slabs & $\begin{array}{l}\text { Concrete } \\
\text { and steel plate }\end{array}$ & Buckling & Efflorescence & Mould growth & 2 & $0.39-0.45-0.67$ \\
\hline $\begin{array}{l}\text { External } \\
\text { fenestration }\end{array}$ & Wood & $\begin{array}{l}\text { Peeling and } \\
\text { bending }\end{array}$ & Efflorescence & $\begin{array}{l}\text { Mould growth } \\
\text { and odours }\end{array}$ & 5 & $0.66-0.99-1.00$ \\
\hline $\begin{array}{l}\text { External } \\
\text { fenestration }\end{array}$ & Coated aluminium & None & $\begin{array}{l}\text { Discoloured } \\
\text { surfaces }\end{array}$ & Corrosion & 1 & $0.19-0.30-0.33$ \\
\hline $\begin{array}{l}\text { External } \\
\text { fenestration }\end{array}$ & $\begin{array}{l}\text { Metal gate } \\
\text { and fence }\end{array}$ & None & $\begin{array}{l}\text { Discoloured } \\
\text { surfaces }\end{array}$ & Corrosion & 1 & $0.27-0.49-050$ \\
\hline External walls & $\begin{array}{l}\text { Cement block } \\
\text { and plaster }\end{array}$ & Cracking & Efflorescence & Mould growth & 4 & $0.51-0.79-0.81$ \\
\hline Floor & Terrazo & None & $\begin{array}{l}\text { Discoloured } \\
\text { surfaces }\end{array}$ & Mould growth & 2 & $0.19-0.42-0.55$ \\
\hline Floor & Ceramic tiles & None & $\begin{array}{l}\text { Discoloured } \\
\text { surfaces }\end{array}$ & Mould growth & 2 & $0.19-0.28-0.30$ \\
\hline Columns & $\begin{array}{l}\text { Concrete and } \\
\text { steel rods }\end{array}$ & Bending & Efflorescence & Corrosion & 2 & $0.19-0.30-0.55$ \\
\hline Foundation & Cast stone & $\begin{array}{l}\text { Flexion and } \\
\text { peeling }\end{array}$ & Efflorescence & $\begin{array}{l}\text { Mould growth } \\
\text { and corrosion }\end{array}$ & 4 & $0.09-0.38-0.52$ \\
\hline
\end{tabular}

After that, the derivation of the depth-physical impact function was carried out. Table 4 relates every susceptible volume of the component to a level of water depth. The water depths are depicted by the blue colour row. The potential degradation for every component continually increases from its lower height until the water level overtakes its upper height, as the water depth rises. Up here, the component degradation is assumed as constant when the flood continues to rise. The sum of the susceptible volume for the impacted components at every water depth is calculated in the green row.

This process was carried out for the three aforementioned and all the other for the derivation of the depth-physical impact functions (Fig. 5). The curves depict the potential deterioration (in $\mathrm{m}^{3}$ ) of the building's integrity. Hence, depending on the water depth, an amount volume in cubic metres is degraded.

The next step consists of the derivation of a synthetic function for every taxonomic code. Then, each building taxonomic code has a median depth-impact function with its respective standard deviation by water depth (see Fig. 6).
The seven synthetic functions of this study area can be transferred as long as the areas have similar conditions of development and are located in the same region, assuming that the buildings share similar construction materials. In this example, the information of median depth-physical impact functions of the representative buildings may be used for the assessment of flood damage to the buildings with similar characteristics located in the northern part of the Magdalena River floodplain.

\section{Discussion}

The testing of the methodology derived from the conceptual framework led to useful results for a large-scale and highresolution physical flood susceptibility assessment for buildings. The combination of the modules 1-3 appeared to be effective in the classification and characterisation of the built structure and the subsequent susceptibility assessment. Overall, the methodology provides a systematic procedure with reduced efforts compared to extensive ex-post damage surveys or ex-ante synthetic damage simulation modelling. A consideration of the entire physical flood vulnerability would 
Table 3. Example of information collected for the analysis of susceptibility - building " 2221123 ".

\begin{tabular}{|c|c|c|c|c|c|c|c|}
\hline & Component & $\begin{array}{l}\text { Lower } \\
\text { height }\end{array}$ & $\begin{array}{l}\text { Upper } \\
\text { height }\end{array}$ & Material & Susceptibility & $\begin{array}{l}\text { Volume material } \\
\text { in } \mathrm{m}^{3}\end{array}$ & $\begin{array}{l}\text { Susceptible } \\
\text { volume in } \mathrm{m}^{3}\end{array}$ \\
\hline \multirow{4}{*}{$\begin{array}{l}\text { Second } \\
\text { floor }\end{array}$} & Roof & 6.4 & 6.6 & $\begin{array}{l}\text { Plate in concrete, steel and } \\
\text { waterproofing }\end{array}$ & 0.31 & 39.22 & 12.16 \\
\hline & $\begin{array}{l}\text { External } \\
\text { fenestration }\end{array}$ & 4.2 & 5.5 & Wood & 0.99 & 4.80 & 4.75 \\
\hline & External walls & 3.4 & 6.4 & Cement block and plaster & 0.79 & 33.08 & 26.14 \\
\hline & Floor & 3.3 & 3.4 & Ceramic tiles & 0.28 & 19.61 & 5.49 \\
\hline \multirow{7}{*}{ First floor } & Slab & 3.1 & 3.3 & Concrete and steel plate & 0.45 & 39.22 & 17.65 \\
\hline & $\begin{array}{l}\text { External } \\
\text { windows }\end{array}$ & 2.5 & 3.0 & Coated aluminium & 0.30 & 1.00 & 0.30 \\
\hline & External walls & 0.2 & 3.0 & Cement block and plaster & 0.79 & 32.08 & 25.35 \\
\hline & External doors & 0.2 & 2.5 & Metal gate and fence & 0.49 & 1.00 & 0.49 \\
\hline & Floor & 0.0 & 0.2 & Terrazo & 0.42 & 19.61 & 8.24 \\
\hline & Columns & -1.0 & 6.6 & Concrete and steel rods & 0.30 & 3.08 & 0.92 \\
\hline & \begin{tabular}{|l|} 
Foundation \\
\end{tabular} & -1.0 & 0.2 & Cast stone & 0.38 & 11.82 & 4.49 \\
\hline
\end{tabular}

Table 4. Derivation of the building's volume degradation for water depths related to the material in Table 3.

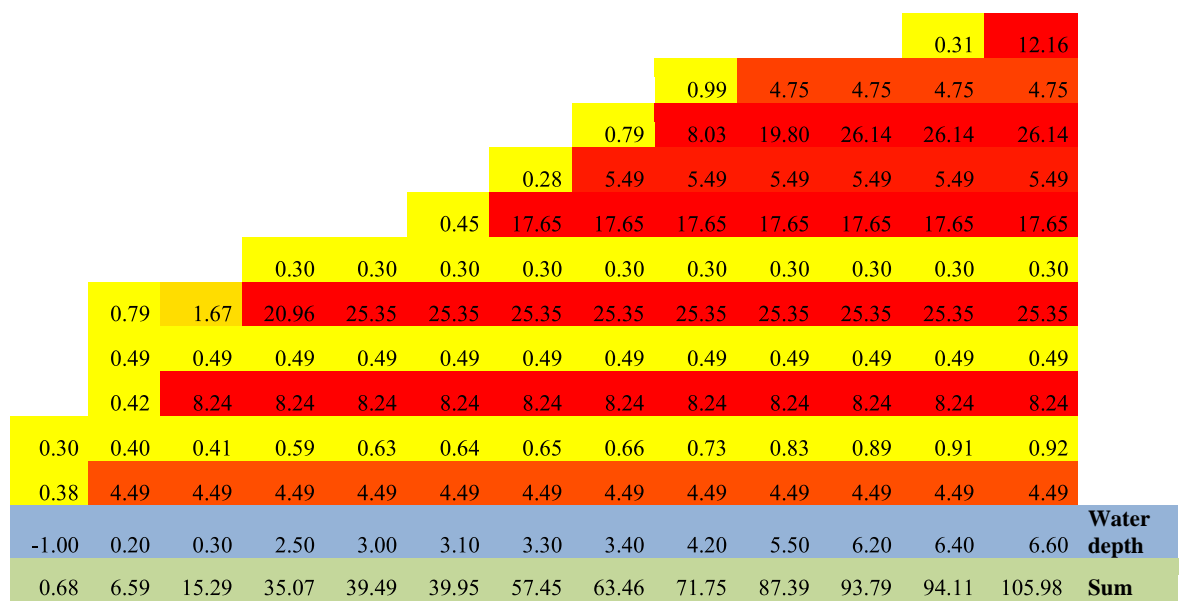

require the operationalisation of both the physical function of construction elements and their coping capacity in terms of physical resilience. To address these two, further research is needed to reach a particular trade-off between physical validity and resource efficiency for the field work. However, an investigation in this respect is likely to be included in the survey already required for the assessment of the physical flood susceptibility.

A transferability of the approach to other study regions seems to depend mainly on the accessibility of very-highresolution data. Although there are currently certain limitations in many regions of the world, improvements may be expected from new sensors. There is a rapidly increasing trend towards the availability and accessibility of spatial data and improvements of their properties in terms of resolution. For instance, unmanned aerial vehicles may be supposed to provide support for the collection of very-high-resolution images and the improved accuracy of the extracted features. Additionally, new free algorithms for extraction of features play a role, such as SpaceEye (ICIS, 2009), which allows processing the global data of Google Earth with simple functions on the imagery, such as segmentation and edge extraction. These technological advances will contribute in the near future to the collection of a huge amount of data which will require classification for the analysis of settlements.

\section{Conclusions}

So far, the conceptual and methodological frameworks presented in this paper are a novel approach with some potential for assessing the physical flood susceptibility on a large scale. The implemented and tested methodology can prepare detailed civil engineering analyses in hotspot areas as well as further social and economic vulnerability analyses.

The concept of flood vulnerability allows for the decomposition of methods for the physical flood susceptibility assessment. These methods, which are bundled in modules, can 


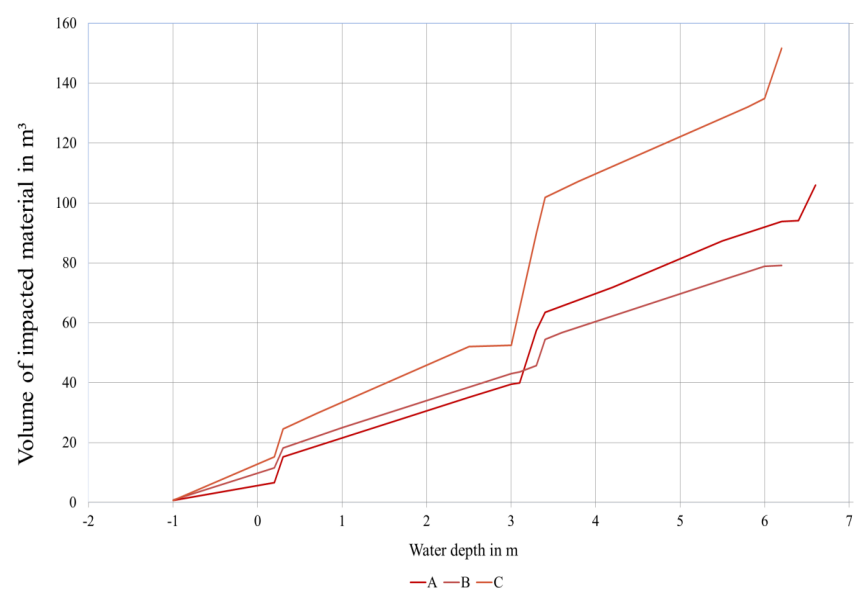

Figure 5. Depth-physical impact functions for the buildings A, B and $\mathrm{C}$.

support an initial estimation of potential flood impacts on buildings.

According to the literature, a very-high-data resolution of images and digital surface models are required for the extraction of building features. The parameters building height, building size, elongatedness, roof form, roof slope, compactness and adjacency can be derived from these features.

In the selected study case, semi-automatic and manual processing was carried out for the building's outline extraction, and the values of building height and roof slope were automatically extracted and verified in the survey.

The reliability of the extraction of the parameters depends on the accuracy of the building outline or building footprint, the resolution of the digital surface model and the complexity of the area.

The building taxonomic code composed of seven parameters can help experts to identify the relevant structural characteristics of a building. It should be appropriate for any region and can serve as a vehicle for transferring patterns of variables of settlements. It condenses the parameters in a brief format, establishing a clear link among the buildings' geometrical characteristics, and is extensible, adaptable and transferable to other study areas. It is also a trustful, standard and automatic method, which helps to simplify the communication between the users who are dealing with building structure surveys in urban areas. The validity of this building typology is borne out visually comparing pictures of the buildings with the obtained parameters of the taxonomic code. It is a valuable and reliable source of information, which can be used for synthesising field works also in other types of applications, such as social science researches (e.g. living condition index, demographic studies, service availability), economic researches (e.g. insurance schemes, cadastral appraisals), energy assessments (e.g. Loga et al., 2012) and the assessment of other types of vulnerabilities.

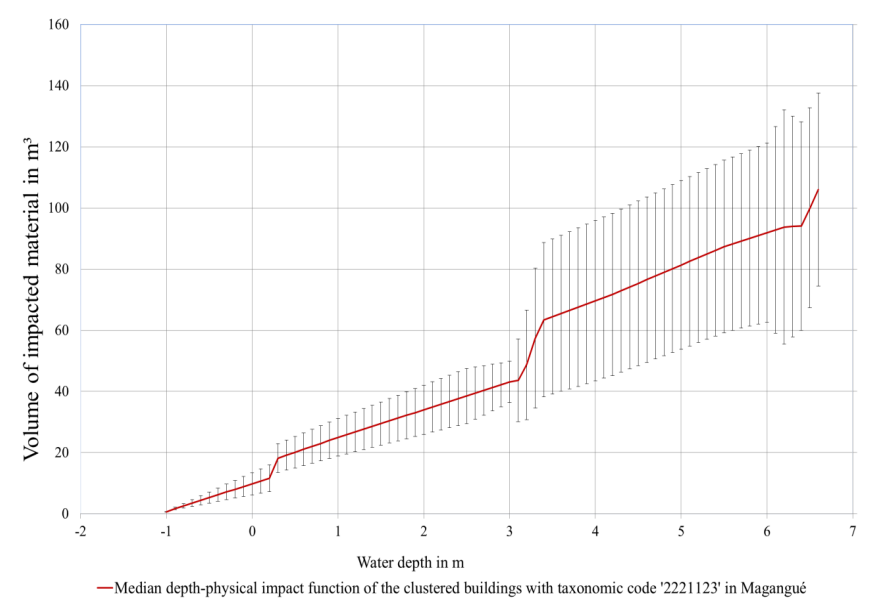

Figure 6. Median and standard deviation of the depth-physical impact functions for the three taxonomic-code buildings " 2221123 " in Magangué, Colombia.

Statistical and cluster analyses are a good means to select representative buildings and group non-representative buildings to representative buildings by using a membership function. This generates a value of matching, which indicates the degree of similarity between a building and a representative building. The approach of selecting the representative buildings via the building taxonomic code can help to reduce costs and time required for surveying information in urban areas; because it makes the collection of data in the field more effective and also allows to transfer knowledge on the building structure.

The determination of the material's susceptibility involves many uncertainties and different interpretations from the experts; something that is susceptible for one expert has another interpretation for the other. Here, the attempt to reduce these uncertainties is done by integrating scientific and local knowledge. Two steps can be carried out for its approximate determination: (i) the provision of information on the material's resistance assuming that susceptibility is the opposite of resistance, incorporating the resistance values from international approaches (e.g. BMVBS, 2006; Committee and Resources, 2006; Escarameia et al., 2006; FEMA, 2008); and (ii) the assessment of the material's properties based on the expert whose knowledge allows determining the uncertainties associated with the vagueness of the material's susceptibility. It is important to store and evaluate this information in order to distinguish which building materials can suffer cracks, flaking, strain, brittleness, shrinkage, deflection, bending stress, buckling, shearing, expansion or residual stress that affects the proper functionality after an inundation.

The derivation of depth-physical impact functions requires a structured collection of information on the relevant components of the representative buildings, such as their relevant materials, the materials' properties for their suscepti- 
bility qualification, their related dimensions such as width, length and thickness as well as the location above the terrain (lower height and upper height). Hereby, depth-physical impact functions are seen as a means of interrelation between the water depth and the degraded volume of the building's materials per component. The median depth-physical impact function is a synthetic function for every taxonomic code that reflects the range of potential impacts which a group of buildings with similar characteristics can receive. This function may provide the basis for a subsequent derivation of a depth-damage function as basic indicator for economic vulnerability and social vulnerability.

Taking advantage of the technological advances in data collection, such as GPS in smart phones, apps, data storing (e.g. a database in PostgreSQL) and data processing (e.g. Python scripts), new tools were developed for simplification and control processes. They refer to a derivation of the taxonomic code for each building, the selection of representative buildings and the integration of the methods for a building susceptibility assessment.

As future work, the depth-physical impact functions should be tested for supporting the analysis of other types of vulnerabilities, assisting damage detection, refurbishment costs and estimation of the loss with monetary value. The material lists of the four mentioned institutions with their resistance classes may be extended on the basis of the qualification of the material's properties, increasing the knowledge about various building materials in developing countries. This information may promote the calculation of the susceptible volume for components in representative buildings supporting detailed civil engineering analyses.

Acknowledgements. We are grateful to the International Postgraduate Studies in Water Technology Programme (IPSWaT), funded by the German Federal Ministry of Education and Research (BMBF). We would like to thank the IGAC in Colombia for providing data for testing the methodology in Colombia. We are also grateful to Haala of the University of Stuttgart, and Behnisch, Naumann, Nikolowski and Schinke of the IOER for their valuable advice. We acknowledge Abello of Atlántico University in Colombia for supporting the qualification of the materials' susceptibility.

Edited by: H. de Moel

Reviewed by: two anonymous referees

\section{References}

Adriaans, P. and Zantinge, D.: Data Mining, Pearson Education. New Delhi, India, 1996.

Aglan, H., Wendt, R., and Livengood, S.: Field Testing of EnergyEfficient Flood-Damage Resistant Residential Envelope Systems Summary Report, available from: http://www.ibsadvisorsllc. com/_library/ORNL_Field_Testing_of_Energy_Efficient_ Flood_Damage_Resistant_Residential_Envelope_Systems.pdf (last access: 15 August 2013), 2004.
Aguilar, F. J. and Mills, J. P.: Accuracy assessment of lidar-derived digital elevation models, The Photogrammetric Record, 23, 148169, 2008.

Awrangjeb, M., Ravanbakhsh, M. and Fraser, C. S.: Automatic detection of residential buildings using LIDAR data and multispectral imagery, ISPRS J. Photogramm. Remote Sens., 65, 457-467, 2010.

Birkmann, J.: Measuring vulnerability to promote disaster-resilient societies: Conceptual frameworks and definitions, edited by: J. Birkmann, Measuring Vulnerability to Natural Hazards, 01, 954, 2006.

Blaikie, P., Cannon, T., Davis, I., and Wisner, B.: At Risk: Natural Hazards, People's Vulnerability and Disasters, Taylor \& Francis, ISBN: 9780203974575, 1994.

Blanco-Vogt, A., Haala, N., and Schanze, J.: Building extraction from remote sensing data for parameterising a building typology: a contribution to flood vulnerability assessment, JURSE Conference Sao Paulo, 147-150, 2013.

BMVBS: Hochwasserschutzfibel. Bauliche Schutz- und Vorsorgemaßnahmen in hochwassergefährdeten Gebieten, available from: http://www.elementar-versichern.bayern.de/ Hochwasserschutzfibel.pdf (last access: 25 September 2013), 2006.

Brauch, H. G. and Oswald Spring, Ú.: Introduction: Coping with Global Environmental Change in the Anthropocene, edited by: H. G. Brauch, Ú. Oswald Spring, C. Mesjasz, J. Grin, P. KameriMbote, B. Chourou, P. Dunay, and J. Birkmann, Springer Berlin Heidelberg, 31-60, 2011.

Brenner, C.: Building extraction, edited by: G. Vosselman and H.-G. Maas, CRC Press, Scotland, 169-212, 2010.

Brzev, S., Scawthorn, C., Charleson, A. and Langenbach, R.: Proposed GEM Taxonomy: $\beta$ ver. 0.1, Global Earthquake Model, http://www.nexus. globalquakemodel.org/gem-building-taxonomy/posts/ updated-gem-basic-building-taxonomy-v1.0 (last access: 25 September 2013), 2011.

Committee and Resources: Reducing Vulnerability of Buildings to Flood Damage: Guidance on Building in Flood Prone Areas, Hawkesbury-Nepean Floodplain Management Steering and New South Wales Dept of Natural, available at: http://www.ses.nsw.gov.au/content/documents/pdf/resources/ Building_Guidelines.pdf (last access: 25 September 2013), 2006.

Coppi, R., Gil, M. A., and Kiers, H. A. L.: The fuzzy approach to statistical analysis, Computat. Statist.Data Anal., 51, 1-14, available at: http://www.sciencedirect.com, 2006.

Escarameia, M., Karanxda, A., and Tagg, A.: Improving the flood resilience of buildings through improved materials, methods and details, report $\mathrm{Wp} 5 \mathrm{c}$ laboratory tests interim report, http://www.ciria.org.uk/flooding/pdf/WP5\%20Lab\% 20Testing\%20Report.pdf (last access: 25 September 2013), 2006.

Evans, E., Hall, J., Thorne, C., Penning-Rowsell, E., Watkinson, A., and Sayers, P.: Future flood risk management in the UK, Proceedings of the Institution of Civil Engineers, Water Management 159, issue WM1, 53-61, 2006.

FEMA, E. M. I.: Flood Damage-Resistant Materials Requirements for Buildings Located in Special Flood Hazard Areas in accordance with the National Flood Insurance Program, (last access: 25 September 2013), 2008. 
Fugate, D., Tarnavsky, E., and Stow, D.: A Survey of the Evolution of Remote Sensing Imaging Systems and Urban Remote Sensing Applications, edited by: T. Rashed and C. Jürgens, Remote Sensing and Digital Image Processing, 10(Chapter 7), 119-139, 2010 .

Haithcoat, T., Song, W., and Hipple, J.: Building Extraction LIDAR R\&D Program for NASA/ICREST Studies, available at: http://www.grc.missouri.edu/icrestprojarchive/NASA/ FeatureExtraction-Buildings/REPYear2-build-extraction.pdf (last access: 25 June 2012), 2001.

Hong, T.-P. and Lee, C.-Y.: Induction of fuzzy rules and membership functions from training examples, Fuzzy Set. Syst., 84, 3347, 1996.

ICIS: Simple Google Earth Image Enhancement With SpaceEye, Image Processing and Intelligent Systems Laboratory, School of Electronic Information, Wuhan University, China., 2009.

Jongman, B., Kreibich, H., Apel, H., Barredo, J. I., Bates, P. D., Feyen, L., Gericke, A., Neal, J., Aerts, J. C. J. H., and Ward, P. J.: Comparative flood damage model assessment: towards a European approach, Nat. Hazards Earth Syst. Sci., 12, 3733-3752, doi:10.5194/nhess-12-3733-2012, 2012.

Kreibich, H., Seifert, I., Merz, B., and Thieken, A. H.: Development of FLEMOcs - a new model for the estimation of flood losses in the commercial sector, Hydrol. Sci. J., 55, 1302-1314, 2010.

Loga, T., Diefenbach, N., Dascalaki, E., and Balaras, C.: Application of Building Typologies for Modelling the Energy Balance of the Residential Building Stock: TABULA Thematic Report $\mathrm{N}^{\circ} 2$, edited by: Diefenbach, N. and Loga, T. E., Institut Wohnen und Umwelt GmbH http://www.building-typology.eu/ tabula.html (last access: 25 September 2013), 2012.

MacQueen, J.: Some methods for classification and analysis of multivariate observations, University of California Press, Los Angeles, 281-297, 1967.

McGahey, C., Mens, M., Sayers, P., Luther, J., Petroska, M., and Schanze, J.: Methodology for a DSS to support long-term flood risk management planning, http://www.floodsite.net/html/partner_area/project_docs/T18_ 09_02_Methodology_DSS_D18_2_V1_1_P01.pdf (last access: 25 September 2013), 2009.

Merz, B., Kreibich, H., Thieken, A., and Schmidtke, R.: Estimation uncertainty of direct monetary flood damage to buildings, Nat. Hazards Earth Syst. Sci., 4, 153-163, doi:10.5194/nhess-4-1532004, 2004.

Mesev, V.: Classification of Urban Areas: Inferring Land Use from the Interpretation of Land Cover, edited by: Rashed, T., Jürgens, C., and Meer, F. D., Springer Netherlands, 141-164, 2010.

Messner, F., Penning-Rowsell, E., Green, C., Tunstall, S., Veen, A. V. D., Tapsell, S., Wilson, T., Krywkow, J., Logtmeijer, C., and Fernández-Bilbao, A.: Evaluating flood damages: guidance and recommendations on principles and methods, Contract, 178 ), http://www.floodsite.net/html/partner_area/project_docs/T09_ 06_01_Flood_damage_guidelines_D9_1_v2_2_p44.pdf (last access: 25 September 2013), 2007.

Meyer, V. and Messner, F.: National Flood Damage Evaluation Methods. A Review of Applied Methods in England, the Netherlands, the Czech Republic and Germany, available from: http:// www.econstor.eu/bitstream/10419/45193/1/505414783.pdf (last access: 25 September 2013), 2005.
Naumann, T., Nikolowski, J., Golz, S., and Schinke, R.: Resilience and Resistance of Buildings and Built Structures to Flood Impacts - Approaches to Analysis and Evaluation, in German Annual of Spatial Research and Policy 2010, edited by: Müller, B., Springer Berlin Heidelberg, 89-100, available at: http://dx.doi. org/10.1007/978-3-642-12785-4_9, 2011.

Navulur, K.: Multispectral image analysis using the objectoriented paradigm, Remote Sensing Applications Series, CRC Press/Taylor \& Francis, Boca Raton, 2006.

Neubert, M., Naumann, T., Hennersdorf, J., and Nikolowski, J.: The Geographic Information System-based flood damage simulation model HOWAD, J. Flood Risk Manag., n/a-n/a, doi:10.1111/jfr3.12109, 2014.

Ochshorn, J.: Structural Elements for Architects and Builders: Design of columns, beams, and tension elements in wood, steel, and reinforced concrete, Elsevier Science, Oxford, UK, 2009.

Rutzinger, M., Rottensteiner, F., and Pfeifer, N.: A comparison of evaluation techniques for building extraction from airborne laser scanning, in: IEEE Journal of Selected Topics in Quantum Electronics 2/1, 11-20, available at: http://www.isprs. org/proceedings/XXXVIII/3-W8/papers/p69.pdf (last access: 25 September 2013), 2009.

Samuels, P., Gouldby, B., Klijn, F., Messner, F., Van Os, A., Sayers, P., Schanze, J., and Udale-Clarke, H.: Language of Risk - Project Definitions (2nd Edn.), http://www.floodsite.net/html/partner_ area/search_results3b.asp?docID=747 (last access: 25 September 2013), 2009.

Scawthorn, C., Blais, N., Seligson, H., Tate, E., Mifflin, E., Thomas, W., Murphy, J., and Jones, C.: HAZUS-MH Flood Loss Estimation Methodology, in: Overview and Flood Hazard Characterization, Natural Hazards Review, 7, 60, 60-71, 2006.

Schanze, J.: Flood Risk Management - A Basic Framework, in: Flood risk management - Hazard, vulnerability and mitigation measures, edited by: Schanze, J., Zeman, E., and Marsalek J., Springer Netherlands, 1-20, 2006.

Schöpfer, E., Lang, S., and Strobl, J.: Segmentation and ObjectBased Image Analysis, Springer Netherlands, 141-164, 2010.

Sohn, G. and Dowman, I.: Data fusion of high resolution satellite imagery and LiDAR data for automatic building extraction, ISPRS J. Photogramm. Remote Sens., 62, 43-63, 2007.

Thywissen, K.: Components of Risk: A Comparative Glossary, http://www.ehs.unu.edu/file/get/8335 (last access: 25 September 2013), 2006.

UNEP: Geo-3: global environment outlook. Chapter 3:Human Vulnerability to Environmental Change, http://www.grida.no/geo/ geo3/english/pdfs/chapter3_vulnerability.pdf (last access: 25 September 2013), 2002.

UNISDR, 2004: Terminology: Basic terms of disaster risk reduction. Reduction Strategy International For Disaster, www. unisdr.org/files/7817_7819isdrterminology11.pdf (last access: 25 September 2013), 2004.

Vu, T. T. and Ban, Y.: Context-based mapping of damaged buildings from high-resolution optical satellite images, Internat. J. Remote Sens., 31, 3411-3425, 2010.

WHO: Guidelines for indoor air quality: dampness and mould, www.euro.who.int/document/e92645.pdf (last access: 25 September 2013) 1-248, 2009. 